\title{
Growth and Fluctuations: A Causal Interpretation
}

\section{Citation}

Jorgenson, Dale W. 1960. Growth and fluctuations: A causal interpretation. Quarterly Journal of Economics 74(3): 416-436.

\section{Published Version}

http://dx.doi.org/10.2307/1883059

\section{Permanent link}

http://nrs.harvard.edu/urn-3:HUL.InstRepos:3403056

\section{Terms of Use}

This article was downloaded from Harvard University's DASH repository, and is made available under the terms and conditions applicable to Other Posted Material, as set forth at http:// nrs.harvard.edu/urn-3:HUL.InstRepos:dash.current.terms-of-use\#LAA

\section{Share Your Story}

The Harvard community has made this article openly available.

Please share how this access benefits you. Submit a story.

Accessibility 


\section{IIIII| The MIT Press}

Growth and Fluctuations: A Causal Interpretation

Author(s): Dale W. Jorgenson

Source: The Quarterly Journal of Economics, Vol. 74, No. 3 (Aug., 1960), pp. 416-436

Published by: The MIT Press

Stable URL: http://www.jstor.org/stable/1883059

Accessed: 07 $/ 11 / 2009$ 10:57

Your use of the JSTOR archive indicates your acceptance of JSTOR's Terms and Conditions of Use, available at http://www.jstor.org/page/info/about/policies/terms.jsp. JSTOR's Terms and Conditions of Use provides, in part, that unless you have obtained prior permission, you may not download an entire issue of a journal or multiple copies of articles, and you may use content in the JSTOR archive only for your personal, non-commercial use.

Please contact the publisher regarding any further use of this work. Publisher contact information may be obtained at http://www.jstor.org/action/showPublisher?publisherCode=mitpress.

Each copy of any part of a JSTOR transmission must contain the same copyright notice that appears on the screen or printed page of such transmission.

JSTOR is a not-for-profit service that helps scholars, researchers, and students discover, use, and build upon a wide range of content in a trusted digital archive. We use information technology and tools to increase productivity and facilitate new forms of scholarship. For more information about JSTOR, please contact support@jstor.org. 


\title{
GROWTH AND FLUCTUATIONS: A CAUSAL INTERPRETATION
}

\author{
By Dale W. Jorgenson
}

I. Introduction, 416. - II. The dynamic input-output system, 420.III. Stability of the dynamic input-output system: investment policy, 423. IV. Stability of the dynamic input-output system: output policy, $430 .-\mathrm{V}$. Summary and conclusion, 434 .

\section{INTRODUCTION}

A steady growth path of outputs for the dynamic input-output system $^{1}$ with a constant rate of growth in each sector of the economy is an equilibrium of the system in a highly restricted sense. There is a set of positive output proportions and an associated constant rate of growth which satisfy the equations defining equilibrium for the system. ${ }^{2}$ It is not as yet clear whether this equilibrium will persist once established or whether the equilibrium so established is stable. Stability as usual has two senses: first, global stability requires that for arbitrary initial output levels, the unique equilibrium output proportions will be attained after some sufficiently long period of time; secondly, local stability implies that for small shocks, whatever their origin, the system will return to its equilibrium path. In previous work on the dynamic input-output system it has been shown that the system describing output time-paths has a dual interpretation determining a time-path of relative prices for all goods in the economy. ${ }^{3}$ Consideration of the stability of the output system and its dual reveals a dual instability theorem: If the output system is stable, the dual or price system must be unstable, both locally and globally. The converse is also true. ${ }^{4}$ If the output system is unstable, the price system

1. See especially: W. W. Leontief, "Dynamic Analysis," in Studies in the Structure of the American Economy, ed. W. W. Leontief (New York: Oxford University Press, 1953), pp. 53-92. Further discussion of the system and a nearly complete bibliography may be found in: R. M. Solow, "Competitive Valuation in a Dynamic Input-output System," Econometrica, Vol. 27 (Jan. 1959), pp. 30-53.

2. For proof of these facts, see: R. Dorfman, P. A. Samuelson, and R. M. Solow, Linear Programming and Economic Analysis (New York: McGraw-Hill, 1958), p. 297, fn. 1.

3. Solow, op. cit.; also: M. Morishima, "Prices, Interest, and Profits in a Dynamic Leontief System," Econometrica, Vol. 26 (July 1958), pp. 358-80; further references are given in Solow's paper.

4. Proof is given by: D. Jorgenson, "On a Dual Stability Theorem," Econometrica, forthcoming. 
may also be unstable; this state of affairs appears to prevail in all empirical dynamic input-output systems so far derived. ${ }^{5}$ These results suggest that as it stands the dynamic input-output system is an incomplete model of the economic system.

Two proposals have been made for completing the system: The first is to make the accumulation of stocks irreversible; stocks may be accumulated at any rate whatever; but they can be decumulated only at a rate equal to the wearing out of capital equipment. ${ }^{6}$ No way has been found to implement this notion econometrically; the well-known switching problem offers serious obstacles to empirical work based on irreversibility. ${ }^{7}$ A second proposal is to interpret the system as a model of optimal capital accumulation. ${ }^{8}$ This interpretation is of interest for applications of the dynamic input-output system to the planning of economic development. There is no evidence at present that a model of capital accumulation involving explicit maximization would be useful in explaining the operation of any actual economic system.

In this paper we present a third proposal for completing the dynamic input-output system. This proposal is to imbed the system in a disequilibrium theory, that is, a theory which purports to explain the behavior of an economic system which is not in long-run equilibrium growth. The source of this theory is in a series of hypotheses about short-run reactions of entrepreneurs to disequilibrium situations, drawn mainly from the older literature on processes of cumulative expansion and contraction during business cycles. ${ }^{9}$ It is

5. Several examples, which are to be taken as illustrative, are given in: K. Iversen, Machine Solutions of Linear Differential Equations, unpublished Ph.D. thesis, Harvard University, 1954.

6. This proposal has been made by Leontief, op. cit.

7. The switching problem is discussed by Leontief, op. cit., by M. McManus, "Self-contradiction in Leontief's Dynamic Model," Yorkshire Bulletin of Economic and Social Research, Vol. 6 (May 1957), pp. 1-21, and by H. Uzawa, "Note on Leontief's Dynamic Input-output System," Proceedings of the Japan Academy, Vol. 32 (Feb. 1956), pp. 79-82.

8. This proposal has been discussed from the point of view of linear programming by H. Uzawa, "On the Efficiency of Leontief's Dynamic Input-output System," Proceedings of the Japan Academy, Vol. 32 (Mar. 1956), pp. 157-60, by $\mathrm{H}$. Wagner, "A Linear Programming Solution to Dynamic Leontief Type Models," Management Science, Vol. 3 (April 1957), pp. 234-54, by Dorfman, Samuelson, and Solow, op. cit., Chap. 11, pp. 281-300; and more recently by M. Morishima, op. cit., and R. Solow, op. cit. Another approach, from the point of view of dynamic programming in the sense of Bellman, is discussed in detail by R. Bellman, Dynamic Programming (Princeton: Princeton University Press, 1957), see especially Chap. VI, "Bottleneck Problems in Multi-Stage Production Processes," and the references listed there.

9. The main source of information on the older theories of the business cycle is, of course: G. Haberler, Prosperity and Depression (2d rev. ed.; Cambridge: Harvard University Press, 1958; 1st ed., 1936). 
postulated that entrepreneurs and other decision-makers react to disequilibrium by altering output and investment policies. In another paper, ${ }^{1}$ disequilibrium reactions to excessive supply and demand, drawn from the classical adjustment mechanisms of Marshall, Walras, and Wicksell, are described and their consequences for stability of the system assessed. Reactions to excessive or deficient inventories or to excess or overstrained capacity of fixed equipment are excluded from consideration. The classical adjustment mechanisms for output levels arise out of consideration of a stationary state situation in which adjustments of stock levels are disregarded. In an economic system in which capital expansion is required for expansion of output, disequilibrium in the level of stocks held is of significance at least equal to that of excess demand or supply.

In what follows we shall discuss disequilibrium reaction mechanisms for excessive or deficient stocks. The fundamental mechanism is based on the notion of some kind of long-run normal quantity of stock of each kind - plant, equipment, and inventory - which entrepreneurs desire to hold. This notion underlies Metzler's analysis of the inventory cycle ${ }^{2}$ and Goodwin's flexible accelerator. ${ }^{3}$ The origin of the underlying idea can be traced back to theories of investment espoused by Kaldor and Kalecki, ${ }^{4}$ and by many earlier writers on the acceleration principle. ${ }^{5}$ When entrepreneurs possess an equilibrium stock level, investment is set so as to expand capacity in accord with expected increases in output levels. However, when stock levels are out of equilibrium, entrepreneurs alter their invest-

1. D. Jorgenson, "On the Stability of the Dynamic Input-output System," Review of Economic Studies, forthcoming.

2. The main references to the work of L. Metzler are: Tho Nature and Stability of Inventory Cycles," Review of Economics and Statistics, XXIII (Aug. 1941), 113-29; "Business Cycles and the Modern Theory of Employment," American Economic Review, XXXVI (June 1946), 278-91; "Factors Governing the Length of Inventory Cycles," Review of Economics and Statistics, XXIX (Feb. 1947), 1-15; "Three Lags in the Circular Flow of Income," in Income Employment and Public Policy, Essays in Honor of Alvin H. Hansen (New York: Norton, 1948), pp. 11-32.

3. R. M. Goodwin, "Secular and Cyclical Aspects of the Multiplier and Accelerator," in Income, Employment and Public Policy, Essays in Honor of Alvin H. Hansen (New York: Norton, 1948), pp. 108-32.

4. N. Kaldor, "A Model of the Trade Cycle," Economic Journal, L (Mar. 1940), 78-92. M. Kalecki, "A Theory of the Business Cycle," Review of Economic Studies, IV (Feb. 1937), 77-97.

5. A complete set of references is given by Haberler, op. cit., p. 87. This theory has recently been revived by Smithies and Duesenberry: A. Smithies, "Economic Fluctuations and Growth," Econometrica, Vol. 25 (Jan. 1957), pp. 1-52. J. S. Duesenberry, Business Cycles and Lconomic Growth (New York: McGraw-Hill, 1958). 
ment plans so as to bring stocks back to normal. The rate at which deficiencies and excesses are reduced is determined by a wide array of economic and technical factors. Although it would be of some interest to examine the effects of such factors individually, it is not possible to go into detail here. The disequilibrium adjustments will be assumed to be of the simplest possible form: The adjustment is proportional to the deficiency or excess. This type of adjustment mechanism is familiar from the theory of stability of the stationary state. $^{6}$ Alternative mechanisms of interest would include upper limits to the decumulation of excess stock - the irreversibility of capital accumulation discussed by many business cycle theorists ${ }^{7}$ upper limits to accumulation in accord with the capacity of investment goods industries ${ }^{8}$ and asymmetry between upward and downward movements in adjustments of capital stock. ${ }^{9}$ The disequilibrium theory to be discussed, when combined with the original dynamic input-output system comprises a complete theory of output determination. The complete system is causal in the sense of Orcutt, Wold, and Simon. ${ }^{1}$ Disequilibrium feeds on itself as in the cumulative process of Wicksell, ${ }^{2}$ providing an interpretation of short-run fluctuations in economic activity as the consequence of disequilibrium. The long-run equilibrium growth path, on the other hand, is determined purely technologically, by input-output and stock-flow relationships which change only slowly over time. The complete system provides a causal interpretation of economic growth and fluctuations.

6. The mechanism considered in the literature is: Price changes are proportional to excess demand. For references to work on stability through 1947, see: P. A. Samuelson, Foundations of Economic Analysis (Cambridge: Harvard University Press, 1947), Part II; for recent references see: K. Arrow, H. Block, and L. Hurwicz, "On the Stability of Competitive Equilibrium, II," Econometrica, Vol. 27 (Jan. 1959), pp. 82-109.

7. Especially, J. R. Hicks, A Contribution to the Theory of the Trade Cycle (London: Oxford University Press, 1950); also: Leontief, op. cit.

8. Hicks, op. cit.

9. L. Koyck, Distributed Lags and the Theory of Investment (Amsterdam: North-Holland Press, 1954).

1. G. Orcutt, "Actions, Consequences, and Causal Relations," Review of Economics and Statistics, XXXIV (Nov. 1952), 305-13; H. Wold (with the assistance of L. Jureen), Demand Analysis (New York: Wiley, 1953); H. Simon, "Causal Ordering and Identifiability," in Studies in Econometric Method, ed. W. Hood and T. Koopmans (New York: Wiley, 1953), pp. 49-74.

2. K. Wicksell, Interest and Prices (London: Macmillan, 1936; 1st ed. (in German), 1898); Lectures on Political Economy, II, Money (London: Routledge, 1935; 1st ed. (in Swedish), 1906). 


\section{The Dynamic Input-output System}

The dynamic input-output system in its closed form is a multisector generalization of the Lundberg-Harrod-Domar growth model. ${ }^{3}$ The system may be written as a system of simultaneous, first-order, linear, differential equations:

$$
x=A x+B \dot{x},
$$

where $x$ is a vector of activity levels; $x_{i}$, the $i$ th component of $x$, represents the rate of output of the $i$ th industry or sector. $A$ is a matrix of input-output coefficients; $a_{i j}$, the element of the $i$ th row and $j$ th column of $A$, is the amount of the $i$ th output required by the $j$ th sector for one unit of its own output. In the one sector version of the system, $A$ is a constant marginal propensity to consume. $B$ is a matrix of stock-flow coefficients so that $b_{i j}$ is the amount of the $i$ th industry's output which must be held by the $j$ th sector for each unit of its own rate of output. In the one sector version $B$ is the "relation" or accelerator coefficient. All output is allocated to two uses: Current consumption in production of other goods and services (including labor services); and accumulation of capital, which is assumed to be strictly proportional to the rate of increase in the output of the accumulating sector. This is easily seen to be a rigid version of the acceleration principle described above. ${ }^{4}$

By noting that the matrix $B^{-1}(I-A)$ is the inverse of a nonnegative matrix, it is easily shown that there is a positive characteristic solution of this system and an associated positive characteristic value. ${ }^{5}$ The positive solution is interpreted as long-run equilibrium output proportions and the characteristic value as a positive rate at which all output levels will be expanding. Moreover, this set of output proportions is unique ${ }^{6}$ so that the rate of growth is the only rate of growth at which all output levels remain non-negative. The condition of non-negativity of output levels is necessary in order

3. It is not well known that the so-called "fundamental equation" of the Harrod-Domar theory of growth was anticipated by E. Lundberg, Studies in the Theory of Economic Expansion (New York: Kelley and Millman, 1954; 1st ed., 1937), p. 185, fn. 1; see also: R. Harrod, Towards a Dynamic Economics (London: Macmillan, 1948); the original discussion is in "An Essay in Dynamic Theory," Economic Journal, XLIX (Mar. 1939), 14-33. E. Domar, Essays in the Theory of Economic Growth (New York: Oxford University Press, 1957); "Capital Expansion, Rate of Growth, and Employment," Econometrica, Vol. 14 (April 1946), pp. 137-47.

4. See above, fn. 5, p. 418 , and the accompanying text.

5. Provided that $B^{-1}$ exists and $B^{-1}(I-A)$ is indecomposable. See: G. Debreu and I. Herstein, "Non-negative Square Matrices," Econometrica, Vol. 21 (Oct. 1953), pp. 597-607.

6. Ibid. 
to retain the economic interpretation of the system. The equilibrium path of the dynamic input-output system is strictly analogous to the Harrod-Domar growth model which it generalizes. There is a positive rate of growth which will persist so long as the system is in equilibrium, that is, so long as the long-run equilibrium output proportions persist. The equilibrium path for the complete dynamic input-output system may be described as follows: (1) All output levels are at capacity and there are no excessive or deficient holdings of stocks; (2) the output of each industry is equal to demands for current consumption and for investment in the expansion of capacity; there are no excess demands or excess supplies for commodities in the economy; (3) finally, the unique positive set of output proportions and the associated constant rate of growth are established.

The stability of this equilibrium path remains to be discussed. In fact there are two separate stability problems. The first is this: Among all output levels which satisfy the equations describing the equilibrium system, is the uniquely positive set of output proportions stable from arbitrary but non-negative initial conditions (global stability) and is it stable for small movements away from the equilibrium proportions such that the equilibrium conditions (1) and (2) are satisfied (local stability)? This is the problem of macro-economic stability discussed by Hawkins, Georgescu-Roegen, and more recently by Dorfman, Samuelson, and Solow. ${ }^{7}$ Macro-economic instability arises when for certain capital structures the unique positive vector of sector output levels is dominated by some other solution of the system, violating the requirement that outputs be non-negative in long-run equilibrium. As we have already indicated, this condition can occur for empirically derived dynamic input-output systems. ${ }^{8}$ If the dynamic input-output model is not macro-economically stable, the economic interpretation of the model cannot be retained. Necessary and sufficient condition for global stability of the equilibrium system, that is, for global macro-economic stability, is that the initial output levels lie in the subspace spanned by characteristic vectors of the system associated with characteristic values smaller in real part than the equilibrium rate of growth. ${ }^{9}$

7. D. Hawkins, "Some Conditions of Macro-economic Stability," Econometrica, Vol. 16 (Oct. 1948), pp. 309-22; N. Georgescu-Roegen, "Relaxation Phenomena in Linear Dynamic Models," in Activity Analysis of Production and Allocation, ed. T. Koopmans (New York: Wiley, 1951), pp. 116-31; Dorfman, Samuelson, and Solow, op. cit.

8. Iversen, op. cit.

9. For proof, see: D. Jorgenson, "On a Dual Stability Theorem," Econometrica, forthcoming. 
Necessary and sufficient condition for local stability of the equilibrium system, that is for local macro-economic stability, is that all perturbations lie in the subspace spanned by characteristic vectors of the system associated with characteristic values less than or equal to the equilibrium rate of growth in real part. ${ }^{1}$

If the dynamic input-output system is not macro-economically stable, the economic interpretation of the model cannot be retained. Therefore, if initial conditions for the system or arbitrary perturbations fail to satisfy the conditions for macro-economic stability, the system must be out of equilibrium. In this state its movement is no longer described by the equilibrium system alone. In what follows we propose the following resolution of the problem of macro-economic instability: First, treat the long-run equilibrium path of outputs as a solution of the equilibrium system, determined technologically by input-output and stock-flow coefficients. Secondly, explain deviations from the conditions required for macro-economic stability by a disequilibrium theory based not on technology but on the activity of decision-makers in a situation of disequilibrium. A further stability problem remains: If the system is not initially in equilibrium will the movement of the disequilibrium variables lead to a re-establishment of long-run equilibrium growth proportions and the associated rate of expansion of all output levels; or is disequilibrium cumulative in the sense that a departure leads farther and farther away from the long-run equilibrium growth path? This second stability problem is analogous to the stability of tatonnements in Walrasian general equilibrium or to stability of the cumulative process of Wicksell. ${ }^{2}$ To resolve this stability problem it is necessary to examine various hypotheses concerning the mechanism by which decision-makers adjust to disequilibrium. Before this task can be undertaken it is necessary to define precisely a set of disequilibrium variables.

If the dynamic input-output system is initially in disequilibrium, output is not equal to demands for output - from current consumption and for current expansion of capacity. The difference between the actual level of output and the required rate is an excess supply of the corresponding commodity, defined as follows:

$$
\xi \equiv x-A x-\dot{B} x
$$

$\xi$ is a vector of excess supplies of the commodities produced by each sector. For example, $\xi_{i}$ is the excess supply of the $i$ th commodity. If $\xi_{i}$ is negative, it represents excess demand for the commodity.

1. For proof, see: Ibid.

2. For references to Walrasian stability analysis, see fn. 6, p. 419. The original discussion is contained in: L. Walras, Elements of Pure Economics (Homewood, Ill.: Irwin, 1954; 1st ed. (in French), 1874); see also: K. Wicksell, op. cit. 
If the level of stocks of the $i$ th commodity held by all sectors in the economy is represented by $s_{i}$, in equilibrium, when all inventories are at desired levels and produstion is at capacity,

$$
s=B x,
$$

the level of stocks held is proportional to the levels of output of each industry holding the stocks. The constant of proportionality is given by $b_{i j}$, the stock-flow coefficient representing the amount of stock of the $i$ th commodity which must be held per unit of output of the $j$ th industry. In the event that there is excess capacity or deficient holdings of stocks, this equality no longer holds. A set of disequilibrium stock variables may then be defined as follows:

$$
\psi \equiv s-B x
$$

where $\psi_{i}$ represents the excess stock of the $i$ th commodity held throughout the economy. If this quantity is negative it represents deficient holdings of the corresponding commodity. By definition the output of any commodity is equal to current consumption plus changes in stocks, whether these changes are desired or not, so that:

$$
x \equiv A x+\dot{s} .
$$

Differentiating the relation defining $\psi$, the vector of excessive stock levels, we obtain:

$$
\psi \equiv \dot{s}-B \dot{s}
$$

so that:

$$
x \equiv A x+B \dot{x}+\dot{\psi}
$$

and the rate of change of excess inventories or excess capacity is equal to the excess supply of the corresponding commodity:

$$
\dot{\psi} \equiv \xi
$$

which is the fundamental stock-flow identity for the disequilibrium system. The problem of disequilibrium analysis is this: What governs the movements of the excessive or deficient stocks, $\psi$ ?

\section{Stability of the Dynamic Input-output System: Investment Policy}

The first disequilibrium mechanism to be discussed is based on the reaction of investment policy to excessive or deficient holdings of stocks. The actual rate of investment is equal to the level necessary to maintain current increases in output, increased or diminished by alterations in the discrepancy between actual and desired holdings of stocks. Investment in the $i$ th commodity, say $\dot{s}_{i}$, is the sum of investments made by each sector which holds commodity $i$ as a stock, just sufficient to maintain the normal stock-flow ratio at current 
output levels. This induced or desired investment level for the $j$ th sector is $b_{i j} \dot{x}_{j}$; the sum of desired or induced investments over all sectors is $\sum_{j=1}^{n} b_{i j} \dot{x}_{j}$. The second component of investment is a change in excessive or deficient holdings of stock which is proportional to preseni excess holdings of all commodities by all sectors. Where the constant of proportionality is $k_{i j}$, representing the proportion of investment in the $i$ th commodity to excess stocks of the $j$ th, the total adjustment of investment levels in the $i$ th commodity throughout the economy is $\sum_{j=1}^{n} k_{i j}\left(s_{j}-\sum_{h=1}^{n} b_{j h} x_{h}\right)$, so that total investment in the $i$ th commodity is given by:

$$
\dot{s}_{i}=\sum_{j=1}^{n} b_{i j} \dot{x}_{j}+\sum_{j=1}^{n} k_{i j}\left(s_{j}-\sum_{h=1}^{n} b_{j h} x_{h}\right), \quad(i=1 \ldots n .)
$$

The relation of this mechanism to Metzler's model of the inventory cycle $^{3}$ may be made more apparent by rewriting the system in matrix form:

$$
\dot{s}=B \dot{x}+K(s-B x),
$$

where $\dot{s}$ is a vector with components $\dot{s}_{i}, B$ is a matrix of stock-flow coefficients, $K$ is a matrix of reaction coefficients, $s$ and $\dot{x}$ are stock and output vectors and $\dot{x}$ is a vector with elements representing the rate of change of outputs.

Recalling from the previous section that total investment is output less current consumption we have:

$$
x-A x=\dot{s}=B \dot{x}+K(s-B x) .
$$

The mechanism may be rewritten as follows:

$$
x=A x+B \dot{x}+K(s-B x)
$$

where $x$ is a vector of output levels, representing current production; $A x+B \dot{x}$ is expected sales or normal long-run demand for each commodity; the difference between current production and normal sales is proportional to (not necessarily equal to) the existing deficiency or excess in holdings of stocks. In Metzler's period analysis, it is postulated that entrepreneurs undertake to remove the entire deficiency or excess in stock in a single period, thereby generating further excesses and deficiencies. More recently, Mills ${ }^{4}$ has given an interpretation of the inventory cycle in which stock adjustment in each

3. See fn. 2, p. 418 for references.

4. E. S. Mills, "Expectations, Uncertainty and Inventory Fluctuations," Review of Economic Studies, XXII (1954-55), 15-22. 
period is proportional to but not equal to the outstanding excess or deficiency. This is the mechanism of adjustment we have attempted to describe here. The adjustment of stocks is proportional to, but not necessarily equal to, the difference between current holdings and desired holdings at the current level of output. ${ }^{5}$

The elements of the matrix of adjustment coefficients $K$ represent the rate of response of investment levels in each industry to excessive or deficient holdings of each commodity as a stock. In a highly decentralized economy, sector output levels are set with reference only to current stocks and current demands for the commodity produced by the sector in question. All off-diagonal elements of $K$ would be zero in this case. Excess demands for any other commodity would affect the output level of a given sector only through effects on orders for that sector's output induced by investment or disinvestment in other commodities. In an economic system which is not perfectly decentralized, excess demand for a commodity might have two possible effects: First, it could lead to an increase in output by the sector, partly to satisfy demands, partly to accumulate inventories; secondly, entrepreneurs in other sectors, perceiving a disequilibrium situation in some other sector than their own would increase their orders for the commodity in short supply to insure their own supply of the commodity and also to hedge against possible changes in relative prices resulting from the disequilibrium. If the rise in speculative demand for the commodity outweighed the increase in output induced by the excess demand, the situation would be worsened. This is the mechanism underlying Harrod's discussion of the instability of the long-run equilibrium growth path. ${ }^{6}$ A simple mechanism satisfying Harrod's requirement that excess demand result in an increase in excess demand has been treated in another paper. ${ }^{7}$ In what follows we will consider the decentralized case; in this case deficient stocks lead to a rise in investment in the commodity, so that $k_{i i}$ is negative for all sectors. Moreover, in the decentralized case it may be assumed that all off-diagonal elements of $K$ are zero; disequilibrium in one sector affects output levels and investment policies in other sectors only through its effect on current consumption and desired accumulation of the commodities produced by the other sectors.

5. This mechanism is, of course, the flexible accelerator of Goodwin; see fn. 3, p. 418 above for reference. A similar, but not identical mechanism is discussed by H. Rose, "The Possibility of Warranted Growth," Economic Journal, LXIX (June 1959), 313-33.

6. Harrod, op. cit.

7. D. Jorgenson, "On the Stability of the Dynamic Input-output System," Review of Economic Studies, forthcoming. 
The stability of the dynamic input-output system under the type of adjustment mechanism envisioned in Metzler's inventory cycle may best be analyzed by still a third interpretation of the adjustment mechanism. First, note that the mechanism may be written:

$$
\dot{s}-B \dot{x}=K(s-B x),
$$

and, recalling that $\psi=s-B x$, where $\psi$ is the excess of actual stocks over desired stocks, this mechanism may be written:

$$
\dot{\psi}=K \psi \text {. }
$$

Then, using the definition of the disequilibrium variables:

$x=A x+B \dot{x}+\dot{\psi}$ the complete system is given by:

$$
\begin{aligned}
& x=A x+B \dot{x}+\dot{\psi} \\
& \dot{\psi}=K \psi .
\end{aligned}
$$

In normalized form this system is written:

$$
\begin{array}{lr}
\dot{x}=B^{-1}(I-A) x & -B^{-1} K \psi \\
\dot{\psi}= & K \psi
\end{array}
$$

which is easily seen to be a decomposable system. ${ }^{8}$

The fact that the complete system is decomposable has two interesting economic implications. First, if the disequilibrium variables are initially zero, the complete system collapses into the dynamic input-output system:

$$
x=A x+B \dot{x}
$$

which is Leontief's original version of the closed system. ${ }^{9}$ A second economic implication of decomposability is that the variables of the complete system may be divided into two sets which are ordered causally in the sense of Wold, Simon, and Orcutt ${ }^{1}$ - the equilibrium variables $x$ and disequilibrium variables $\psi$. The time path of the disequilibrium variables depends only on the values assumed by these variables. In this sense disequilibrium is cumulative in the manner of the classical processes of economic fluctuation in the older literature of the business cycle. A departure from equilibrium generates a reaction which increases or reduces the departure. The equilibrium variables, in this case the levels of output of each sector, are affected by reactions to disequilibrium; excess stocks modify investment policy and thereby levels of output. Along with the familiar elements of the matrix multiplier ${ }^{2}$ and Leontief's multi-sector accelerator,

8. Decomposability is defined by: G. Debreu and I. Herstein, op. cit.

9. Leontief, op. cit.

1. For references see fn. 1, p. 419.

2. For references and discussion, see: R. Solow, "On the Structure of a Linear Model," Econometrica, Vol. 20 (Jan. 1952), pp. 29-46. 
observed levels of output are caused by the existence of disequilibrium in holdings of stocks; however, stock levels remain in equilibrium once the system has returned from disequilibrium. In this sense they are independent of the levels of output achieved in equilibrium.

As we have pointed out earlier, macro-economic stability is essential if the economic interpretation of the system is to be retained. In the event that initial conditions are such that the equilibrium system is not macro-economically stable on the hypothesis that the system is initially in equilibrium, then it must be concluded that the system is out of equilibrium. Necessary and sufficient condition for macro-economic stability in the large and in the small is that the initial conditions for the equilibrium system and all subsequent perturbations must lie in the subspace spanned by characteristic vectors of $B^{-1}(I-A)$ with characteristic value less in real part than the equilibrium rate of growth, ${ }^{3}$ and the equilibrium output proportions associated with this rate of growth. For any set of initial output levels, the initial conditions for the equilibrium system may be represented:

$$
x(0)=X c=X_{1} c_{1}+X_{2} c_{2},
$$

where $X$ is the fundamental matrix of $B^{-1}(I-A)$, that is, the matrix whose columns are characteristic vectors of $B^{-1}(I-A)$. Associated with the initial output levels $x(0)$, there is a unique vector of constants c. If $X_{1}$ is the matrix of characteristic vectors associated with characteristic values less than the equilibrium rate of growth, together with the uniquely non-negative characteristic vector, representing long-run equilibrium output proportions, and $X_{2}$ is the matrix of the remaining characteristic vectors, then for macro-economic stability (global and local) it is necessary and sufficient that $c_{2}=0$. This condition enables us to calculate the initial values of the disequilibrium variables, $\psi(0)$. First, we expand the initial conditions in terms of the fundamental matrix of the complete system, say $Z$ :

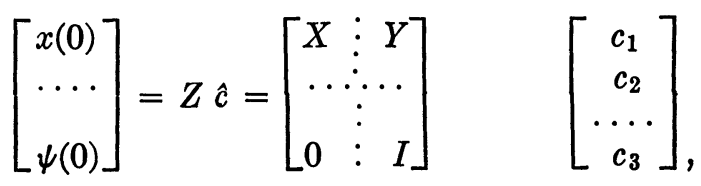

where $X$ is as above (18), $I$ is the identity matrix, and $Y$ is composed of the remaining elements of the last $N$ characteristic vectors of the total system. Now, assuming $c_{1}$ given as the constants corresponding to the "equilibrium" part of the solution, and assuming $c_{2}$ zero, as

3. See above, fn. 9, p. 421 and fn. 1, p. 422 and the accompanying text. 
required by macro-economic stability, we may solve for $c_{3}$ and $\psi(0)$. First, inverting $Z$, we have:

$$
\left[\begin{array}{c}
c_{1} \\
0 \\
\cdots \\
c_{3}
\end{array}\right]=\left[\begin{array}{ccc}
X^{-1} & \vdots & -X^{-1} Y \\
\cdots & \vdots & \cdots \\
0 & \vdots & I
\end{array}\right]\left[\begin{array}{c}
x(0) \\
\cdots \\
\psi(0)
\end{array}\right]
$$

Hence:

$$
\begin{aligned}
{\left[\begin{array}{l}
c_{1} \\
0
\end{array}\right] } & =X^{-1} x(0)-X^{-1} Y \psi(0) \\
c_{3} & =\psi(0)
\end{aligned}
$$

The first of this pair of vector equations may be solved for $\psi(0)$ and hence $c_{3}$, as follows:

$$
\psi(0)=-Y^{-1} X\left[\begin{array}{l}
c_{1} \\
0
\end{array}\right]-Y^{-1} x(0) .
$$

The fundamental problem of the stability of growth, that is, of the tendency of the system toward or away from steady growth equilibrium, must be resolved by empirical investigation. The parameters of the input-output matrix $A$, the stockflow matrix $B$ and the matrix of reaction coefficients $K$ must be estimated from empirical data. For this purpose it is unnecessary to observe excessive or deficient stocks directly. ${ }^{4}$ It is sufficient to observe levels of output in each sector. Since $A$ and $B$ are long-run parameters, they may be estimated from cross-section data. ${ }^{5}$ Then $K$ may be estimated from time series, since the elements of $K$ represent short-run reaction coefficients. Given a series of output levels in each sector, we may utilize the crosssection estimates of $A$ and $B$ as follows: First, we differentiate the disequilibrium relation (14) to obtain:

$$
\ddot{\psi}=K \dot{\psi} \text {. }
$$

But, by definition of the disequilibrium variables we have:

$$
\begin{aligned}
& \dot{\psi}=x-A x-B \dot{x} \\
& \ddot{\psi}=\dot{x}-A \dot{x}-B \ddot{x}
\end{aligned}
$$

4. In the same way and for essentially the same reason it is unnecessary to observe "transitory income" in Friedman's theory of consumption:See M. Friedman, A Theory of the Consumption Function (Princeton: Princeton University Press, 1957).

5. Cross-section data necessary for this purpose are available from the 1947 interindustry study. The basic reference for the input-output matrix is: W. D. Evans and M. Hoffenberg, "The Interindustry Relations Study for 1947," The Review of Economics and Statistics, XXXIV (May 1952), 97-142. The basic reference for the stock-flow matrix is: R. N. Grosse, "Capital Requirements for the Expansion of Industrial Capacity" (Washington, D.C.: Executive Office of the President, Bureau of the Budget, Office of Statistical Standards, Vol. I, Parts 1 and 2, November 30, 1953; mimeographed). 
Hence, the system may be rewritten in the form:

$$
\dot{x}-A \dot{x}-B \ddot{x}=K(x-A x-B \dot{x}) .
$$

From the output series $x$, we may calculate $\Delta x$, the vector of first differences of $x$, which may be used to approximate $\dot{x}$; it would also be necessary to calculate $\Delta^{2} x$ as an approximation to $\ddot{x}$. Then, substituting $\Delta x$ and $\Delta^{2} x$ in the relation (25), we obtain the following estimating form:

$$
\Delta x-A \Delta x-B \Delta^{2} x=K(x-A x-B \Delta x) .
$$

In advance of econometric implementation of the system, it may be noted that since the fundamental matrix of the complete model is decomposable, the characteristic values or intrinsic rates of growth of the characteristic solutions are those of $B^{-1}(I-A)$ and $K$. Since it is required that the equilibrium system be macroeconomically stable in order to retain the economic interpretation of $x$ as a vector of output levels, the characteristic value or rate of growth associated with the long-run equilibrium output proportions is the largest rate of growth of the equilibrium system. For long-run stability of the equilibrium output proportions within the complete system it is required that the characteristic roots of $K$ be less than the equilibrium rate of growth. This condition is sufficient for relative stability of the equilibrium output proportions. ${ }^{6}$ In the case of a decentralized system, the characteristic values of $K$ are simply the elements along the diagonal of $K$, since all other elements are zero. But these elements are negative since deficient stock of a commodity increases the rate of investment in that commodity over the normal rate of investment determined by the expansion of output levels. Hence, in the case of a decentralized system, stability of the dynamic input-output system is assured. This result is contrary to the arguments of Sargan that Harrod's mechanism for stability of growth generalizes to the dynamic input-output system. ${ }^{7}$ A close examination of Sargan's argument reveals that he requires for instability that there be one positive characteristic root of the complete system. But if this root is the equilibrium rate and all other characteristic roots are less than this rate in real part, steady growth equilibrium is stable. A similar misunderstanding of the notion of relative stability underlies Allen's discussion ${ }^{8}$ of the stability of the one-sector version of the dynamic input-output system, the familiar HarrodDomar model of growth.

6. For proof, apply the theorem on relative stability in: D. Jorgenson, "On a Dual Stability Theorem," Econometrica, forthcoming.

7. J. Sargan, "The Instability of the Leontief Dynamic Model," Econometrica, Vol. 26 (July 1958), pp. 381-92.

8. R. G. D. Allen, Mathematical Economics (London: Macmillan, 1957). 
IV. Stability of the Dynamic Input-output System:

\section{OUtPut Policy}

In the previous section, a causal interpretation of growth and fluctuations was developed on the hypothesis that excessive or deficient stocks of goods affect the level of output through their effect on investment policies. If the system for determination of output levels is not in equilibrium, then adjustment follows a causal chain: Excess stocks depress investment levels; depressed rates of investment result in a reduction in output levels. In this section the consequences of an alternative hypothesis are examined, namely, suppose that it is output policy, not investment policy, which entrepreneurs attempt to control. The effects of excess or deficient stocks will be observed not in the actual level of output, but in changes in the level of output. The specific form of the hypothesis is that the rate of change of the output of the $i$ th commodity is equal to the rate of change of demand plus a change which is proportional to the excess stock of the $j$ th commodity. Where the constant of proportionality is represented by $h_{i j}$, the change in the output level of the $i$ th commodity as a result of excessive or deficient holdings of the $j$ th commodity will be $h_{i j}\left(s_{j}-\sum_{k=1}^{n} b_{j k} x_{k}\right)$. The change in the output level of the $i$ th commodity in response to all excessive and deficient stocks is given by the expression:

$$
\sum_{j=1}^{n} h_{i j}\left(s_{j}-\sum_{k=1}^{n} b_{j k} x_{k}\right), \quad(i=1 \ldots n .)
$$

Or, in matrix notation:

$$
H(s-B x)
$$

which is the change of output levels in each sector in response to excessive and deficient stocks, where $s$ is a vector of stock levels, $x$ is a vector of output levels, $B$ is the familiar stock-flow matrix and $H$ is the matrix of reaction coefficients $h_{i j}$. To derive an expression for the total change in output levels, the disequilibrium adjustment must be added to the change in demand. This is the sum of changes in current consumption:

$$
\sum_{j=1}^{n} a_{i j} \dot{x}_{j}, \quad(i=1 \ldots n .)
$$

plus changes in current investment for the expansion of stocks:

$$
\sum_{j=1}^{n} b_{i j} \ddot{x}_{j}, \quad(i=1 \ldots n .)
$$


The rate of change if the $i$ th output level is given by the expression:

$$
\begin{gathered}
\dot{x}_{i}=\sum_{j=1}^{n} a_{i j} \dot{x}_{j}+\sum_{j=1}^{n} b_{i j} \ddot{x}_{j}+\sum_{j=1}^{n} h_{i j}\left(s_{j}-\sum_{k=1}^{n} b_{j k} x_{k}\right), \\
(i=1 \ldots n .)
\end{gathered}
$$

Or, in matrix notation:

$$
\dot{x}=A \dot{x}+B \ddot{x}+H(s-B x),
$$

where $A$ is an input-output matrix and the remaining quantities are defined as above.

In a decentralized economy, the output level of any given sector would depend only on the excess stock of the corresponding commodity. For a centralized economy or one which is imperfectly decentralized, entrepreneurs could be expected to alter their level of output in response not only to changes in orders - current demand but also in response to the anticipation concerning changes in orders. Such anticipations would take into account, among other things, prospective levels of output in other sectors. These prospective levels of output would depend on the current level of stocks in relation to the desired level, for each commodity in the economy. If a sector uses a commodity for which stocks are deficient, it may reduce its level of output in order to conserve its supplies; if a sector sells its output for consumption in any industry in which excessive stocks of that industry's output have arisen, the producing sector may be expected to cut back its own production in anticipation of a diminution of orders. It is not possible to assign a definite direction to the reaction of the output of a sector to excess stocks of the output of any other sector without empirical determination of the actual sign. If the system is decentralized, the output level of each sector depends only on excess stocks of the corresponding commodity; the effects of other excess stocks is indirect: Through adjustments in other output levels, the level of excess or deficiency in stocks of a given sector is altered. In the decentralized case, the matrix of reaction coefficients, $H$ is a diagonal matrix. If output levels increase when stocks are deficient and decrease when stocks are excessive, each of the diagonal elements of $H$ is negative. In this case, the complete system is easily seen to be relatively stable in the sense that disequilibrium movements gradually die out in relation to the over-all upward movement of the economic system.

First, recalling the definition of excess demands (2), the complete system may be written:

$$
\dot{x}=A \dot{x}+B \ddot{x}+\dot{\xi}
$$

where $\dot{\xi}$ is the vector of changes in excess demand levels. Next, 
using the definition of excess demand (or supply) and the fundamental stock-flow identity $(2,8)$, we have:

$$
\dot{x}=A \dot{x}+B \ddot{x}+\ddot{\psi} \text {. }
$$

Now, using the definition of excess stocks, $\psi=s-B x$, the disequilibrium relation has the simple form:

$$
\ddot{\psi}=H \psi \text {. }
$$

Combining this disequilibrium relation with the definition of excess demand and supply (8) we may write the complete system as follows:

$$
\begin{aligned}
& x=A x+B \dot{x}+\dot{\psi}, \\
& \ddot{\psi}=H \psi .
\end{aligned}
$$

This system is easily seen to be decomposable so that it possesses a causal interpretation: The disequilibrium variables affect the set of equilibrium variables representing output levels through the changes in output levels induced by excess or deficient stocks. However, when the system is initially in equilibrium, it continues along an equilibrium path and the levels of excess stock and of excess demand remain at a zero level. In the analysis of adjustments to disequilibrium by means of investment policy, a necessary and sufficient condition for equilibrium, that is, for macro-economic stability of the equilibrium system:

$$
x=A x+B \dot{x}
$$

was that excess stocks are zero for all sectors initially. In this case the complete system collapses into the equilibrium system and its course is then governed by the equilibrium system alone. In the present case, where the rate of change of excess supply depends on the level of undesired stocks, this condition is necessary but not sufficient, for suppose that $\xi=\dot{\psi}$, the level of excess supply is zero; then if $\psi \neq 0$, that is, if undesired stocks are not at zero level for all commodities in the economic system, $\ddot{\psi}$ is not zero and hence $\xi=\dot{\psi}$, the level of excess supply cannot remain at zero. The equilibrium in demand and supply for each commodity cannot persist. Necessary and sufficient condition for an equilibrium such that the complete system is governed by the equilibrium system alone is easily seen to be:

$$
\psi=\dot{\psi}=0 \text {. }
$$

In this case, $\ddot{\psi}$, the rate of change in excess demand or excess supply, is also zero and the complete system is governed by the equilibrium system alone. 
To compute the initial levels of excess stocks, $\psi$, and excess demands, $\dot{\psi}=\xi$, we expand the initial conditions in terms of the fundamental matrix of the complete system:

$$
\left[\begin{array}{l}
x(0) \\
\ldots \\
\psi(0) \\
\dot{\psi}(0)
\end{array}\right]=\left[\begin{array}{cccc}
X & \vdots & Y_{1} & Y_{2} \\
\vdots & & \\
\ldots & \ldots & \ldots & \ldots \\
0 & \vdots & Z_{11} & Z_{12} \\
0 & \vdots & Z_{21} & Z_{22}
\end{array}\right]\left[\begin{array}{c}
d_{1} \\
d_{2} \\
\ldots \\
d_{3} \\
d_{4}
\end{array}\right],
$$

where $X$ is the fundamental matrix of $B^{-1}(I-A)$ and the remaining elements correspond to the remaining characteristic vectors of the complete system (36). In order to calculate the initial values of the disequilibrium variables - excess stocks, $\psi(0)$, and excess demands $\psi(0)$, it is necessary to take into account, not only the condition which is equivalent to macro-economic stability, $d_{2}=0$. It is also necessary to use observations on the actual stock levels in the economic system at any given period of time, the vector $s$, in order to compute the level of excess stocks by the relation:

$$
\psi(0)=s(0)-B x(0)
$$

Then we have two vector equations in the constants $d_{3}, d_{4}$ :

$$
\begin{aligned}
& x(0)=X d_{2}-Y_{1} d_{3}-Y_{2} d_{4}, \\
& \psi(0)=x(0)-B x(0)=Z_{11} d_{3}-Z_{12} d_{4} .
\end{aligned}
$$

Using these equations we obtain:

$$
\begin{aligned}
& x(0)-X d_{2}=Y_{1} d_{3}-Y_{2} d_{4}, \\
& s(0)-B x(0)=Z_{11} d_{3}-Z_{12} d_{4},
\end{aligned}
$$

Or, in matrix notation:

$$
\left[\begin{array}{c}
x(0)-X d_{2} \\
s(0)-B x(0)
\end{array}\right]=\left[\begin{array}{ll}
Y_{1} & Y_{2} \\
Z_{11} & Z_{12}
\end{array}\right] \quad \begin{aligned}
& d_{3} \\
& d_{4}
\end{aligned} .
$$

So that:

$$
\left[\begin{array}{l}
d_{3} \\
d_{4}
\end{array}\right]=\left[\begin{array}{ll}
Y_{1} & Y_{2} \\
Z_{11} & Z_{12}
\end{array}\right]^{-1}\left[\begin{array}{l}
x(0)-X d_{2} \\
s(0)-B x(0)
\end{array}\right] .
$$

These values may then be inserted in the equation for $\dot{\psi}(0)$, to obtain:

$$
\dot{\psi}(0)=Z_{21} d_{3}-Z_{22} d_{4}
$$

which completes the calculation of the initial conditions for the system.

In the case of an imperfectly decentralized economic system, the stability of the model cannot be analyzed prior to econometric 
implementation of the disequilibrium theory. However, for a decentralized system, the characteristic roots of the system are easily seen to be the characteristic values of the matrix $B^{-1}(I-A)$, associated with the equilibrium part of the system, together with characteristic values of the matrix:

$$
\left[\begin{array}{ll}
0 & I \\
H & 0
\end{array}\right]
$$

all of which are imaginary. Each root of this matrix is simply the root of one of the characteristic values of $H$. But in the decentralized case, these roots are imaginary numbers, since the characteristic values of $H$ are all negative. This implies immediately that the unique positive set of output proportions of long-run equilibrium growth are stable within the complete system since the real part of all characteristic roots of the system other than those of the equilibrium system are zero. If the system is initially out of equilibrium, or if shocks drive the economy away from equilibrium growth, a system of oscillations in the adjustment of output levels is set up. Since these oscillations have constant amplitude and fixed period, they continue to be propagated through the economy by means of adjustment of output levels. However, relative to the level of output in each sector, the oscillations gradually die out; that is, the oscillations are purely transitory and will eventually be swamped in the long-run upward movement of the economy. Although the cycles retain constant amplitude measured in terms of output, the amplitude steadily diminishes in relation to the actual level of output, which is rising at the long-run equilibrium rate of growth.

For estimation of the parameters of the equilibrium system, it is possible to eliminate the disequilibrium variables altogether, obtaining an expression for the complete system in terms of the output levels alone. This is as follows:

$$
x-A x-B \dot{x}=H[\ddot{x}-A \ddot{x}-B \ddot{x}] .
$$

The estimating form is obtained by replacing $\dot{x}$ with $\Delta x$, and so on:

$$
x-A x-B \Delta x=H\left(\Delta^{2} x-A \Delta^{2} x-B \Delta^{3} x\right),
$$

where $A$ and $B$ are estimated from cross-section data, as in the mechanism previously considered. $H$ may then be estimated from time series.

\section{Summary and Conclusion}

In this paper we have examined the possibility of resolving the problem of causal indeterminacy in dynamic input-output analysis by means of an explicit disequilibrium theory. We have discussed 
two separate disequilibrium mechanisms: The first is based on the alteration of investment policy, which in a decentralized system may be considered to be primarily an inventory adjustment by the sector for which excess or deficient stocks of output exist. The actual adjustment mechanism is assumed to follow the law of proportional effect: The adjustment of investment levels is proportional to the excess or deficiency in stocks held. A second mechanism is based on disequilibrium adjustments through output rather than investment policy. The adjustment is assumed to be proportional to the excess or deficiency in stocks held. Both mechanisms admit of a unidirectional or causal interpretation. If the system is initially in equilibrium, that is, if the system is initially macro-economically stable, then it will continue in equilibrium until external shocks drive it from the equilibrium path. When the system is out of equilibrium, a new type of stability problem arises: Will it return to the equilibrium path? This stability problem cannot be definitely resolved until the theory of disequilibrium which we have proposed has been implemented econometrically. However, if the assumption of perfect decentralization is a good approximation to reality, it can be stated on a priori grounds that either of the two disequilibrium mechanisms we have discussed implies stable adjustment.

The problem under discussion - macro-economic instability and its consequences - is not peculiar to situations involving direct applications of input-output analysis. Such a problem will arise in any dynamic model which generalizes the Harrod-Domar growth model; in particular, such a problem of macro-economic instability arises in detailed analysis of even simple two-sector models of capital accumulation like those discussed by Marx and recently by Mrs. Robinson. ${ }^{9}$ Theoretical models of this type are essential for investigations of such problems as balance among sectors in economic development and the relation between international trade (sectors are countries) and economic growth. Explicit disequilibrium theory provides one means of retaining the economic interpretation of multi-sector growth models based on the Harrod-Domar theory of growth.

Perhaps equal in importance to the conclusion that the funda-

9. K. Marx, Capital, II (Chicago: Kerr, 1933; 1st ed. (in German) 1885). J. Robinson, The Accumulation of Capital (London: Macmillan, 1956). The fact that the underlying model for such two-sector models of capital accumulation is essentially a closed form of the dynamic input-output system is demonstrated by: M. Morishima, "Some Properties of a Dynamic Leontief System with a Spectrum of Techniques," Econometrica, forthcoming. 
mental notions of the Harrod-Domar theory may form the basis of a multi-sector, multi-industry, or multi-country theory of growth is the conclusion that the equilibrium theory, which has been the basis of much current theoretical work on economic dynamics, is seen to be only a part of the theory of business cycles and growth. The form taken by the disequilibrium theory, with its uni-directional or causal interpretation, provides a direct link between equilibrium theories of growth and fluctuations like those of Harrod, Hicks, and HansenSamuelson ${ }^{1}$ and the older theories of the business cycle based on the cumulative process of Wicksell ${ }^{2}$ and other mechanisms derived from the theory of self-sustaining adjustment processes. In order to retain the economic interpretation of the so-called post-Keynesian theory of growth and fluctuations, it is necessary to restore to consideration precisely those aspects of the economic dynamics which are emphasized in pre-Keynesian or classical theories of prosperity and depression.

University of California, Berkeley

1. Harrod, op. cit.; Hicks, op. cit.; P. A. Samuelson, "Interactions between the Multiplier Analysis and the Principle of Acceleration," Review of Economic Statistics, XXI (May 1939), 75-78; and "A Synthesis of the Principle of Acceleration and the Multiplier," Journal of Political Economy, XLVII (Dec. 1939), 786-97.

2. Wicksell, op. cit. 